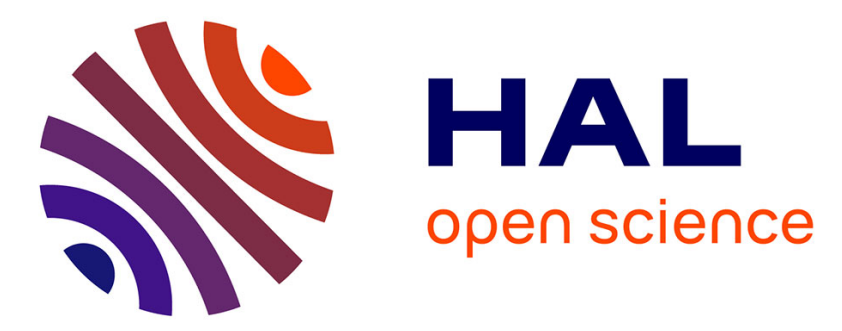

\title{
Low-frequency induction heating of a ferromagnetic catheter for the varicose veins treatment: a study of feasibility
}

Y. Liu, Z. Xiang, J. Garcia, B. Newell, M.Q. Q Le, Benjamin Ducharne

\section{- To cite this version:}

Y. Liu, Z. Xiang, J. Garcia, B. Newell, M.Q. Q Le, et al.. Low-frequency induction heating of a ferromagnetic catheter for the varicose veins treatment: a study of feasibility. 2021 IEEE International Magnetic Conference (INTERMAG), Apr 2021, LYON, France. pp.1-5, 10.1109/INTERMAG42984.2021.9579639 . hal-03435888

\section{HAL Id: hal-03435888 \\ https://hal.science/hal-03435888}

Submitted on 19 Nov 2021

HAL is a multi-disciplinary open access archive for the deposit and dissemination of scientific research documents, whether they are published or not. The documents may come from teaching and research institutions in France or abroad, or from public or private research centers.
L'archive ouverte pluridisciplinaire HAL, est destinée au dépôt et à la diffusion de documents scientifiques de niveau recherche, publiés ou non, émanant des établissements d'enseignement et de recherche français ou étrangers, des laboratoires publics ou privés. 


\title{
Low frequency induction heating of a ferromagnetic catheter for varicose veins treatment: study of feasibility.
}

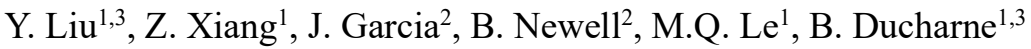 \\ ${ }^{1}$ Laboratoire de Génie Electrique et Ferroélectricité, INSA Lyon, FRANCE. \\ ${ }^{2}$ School of Engineering Technology, Purdue University, IN USA. \\ ${ }^{3}$ ELyTMaX UMI 3757, CNRS - Université de Lyon - Tohoku University, International Joint Unit, Tohoku University, Sendai, \\ JAPAN.
}

\begin{abstract}
Low Frequency Induction Heating (LFIH) phenomena take place in a ferromagnetic catheter under the influence of a low frequency magnetic excitation field. This contactless heat source can be used to heal locally and destroy damaged blood vessels. According to medical specialists, thermal ablation of varicose veins requires a temperature of $120^{\circ} \mathrm{C}$ and time constants lower than a few seconds. Preliminary investigation results showed great potential of the LFIH method, but further testing and validation steps are still needed before in vivo testing can commence. In this article, multi-physics simulation results, including ferromagnetic, thermal and fluid mechanics considerations are proposed and compared to experimental data when possible. The most efficient magnetic waveform (frequency) is selected based on its influence on human tissues. These results constitute a mandatory step towards a preliminary medical testing and the overall medical certification of this alternative treatment.
\end{abstract}

Index Terms - Ferromagnetic catheter, induction heating, varicose veins treatment.

\section{INTRODUCTION}

\section{A. Additive manufacturing}

Additive manufacturing (also called three-dimensional (3D) printing) consists of designing a three-dimensional object from a computer-aided design program (CAD) and building it by successively adding material layer by layer [1][2]. Additive manufacturing in the industrial field is mostly used for conceptual prototypes rather than functional components due to the lack of strength and functionality of 3D printed parts. 3D printing of polymer composites combining polymer-based materials and particle or fiber reinforcements is a practical alternative to increase the strength of the printed part [3]. 3D printing lends itself to the production of components with enhanced characteristics (thermal, mechanical, optical, etc.) or remarkable multi-physics coupling functionalities (ferromagnetic, ferroelectric, etc.). 3D printable magnetic composites are thermo-polymer based materials filled with ferromagnetic particles [4][5]. By combining ferromagnetism with the flexibility of additive manufacturing, the resulting composites have utility in various industrial applications, including: self-healing polymers [6]-[8], thermoplastic induction welding [9]-[12], magnetic cores [13] and even medical applications like the ferromagnetic catheter described in this manuscript [14]-[15].

\section{B. Medical application}

Varicose veins are superficial veins exhibiting anomalous size or undesired twists. They usually result in few symptoms but some may experience pain in adjacent areas. Complications may include bleeding and inflammations [16]. Varicose vein treatments can be either conservative or active. A few years ago, active treatments were highly invasive requiring surgical interventions, but new methods including endovenous laser treatment [17], steam vein sclerosis [18], radiofrequency ablation [19] and foam sclerotherapy are interesting less invasive alternative options. All these methods rely on the same principle: the thermal obliteration of veins through electrocoagulation. The endovenous laser treatment uses an optical fiber inserted into the damaged vein. Laser light in the infrared spectrum shines into the interior of the vein, and causes the vein to contract. Once the local contraction is over, the optical fiber is slowly withdrawn, and the coagulation process begins. Steam vein sclerosis is more versatile. A catheter is connected to a steam-emitting hand piece and carries the steam into the vein. $120^{\circ} \mathrm{C}$ steam pulses are emitted and coagulation is reached in a relatively short time. Even large veins usually stripped surgically can be treated without side-effects using this method. Laser ablation and steam sclerosis are minimally invasive and can easily be performed under local anesthesia, without the need for spinal or general anesthesia. The recovery is fast and postoperative pain is limited. However, technical difficulties can occur during the preoperative healing process, even when a highly experienced doctor is introducing the guide wire, laser fiber or steam micro-tube, perforation is always possible. Bringing heat through conductive supports results in excessive geometrical dimensions and creates undesired size limitations.

\section{Introduction}

In this study, an alternative solution solving the geometrical limitations is described. We propose to transfer heat through a contactless method. A flexible 3D printed ferromagnetic catheter is subjected to an alternating magnetic excitation. Under the influence of the magnetic excitation, eddy currents are generated through the catheter creating heat. First published results [14][15] have demonstrated the feasibility of heat generation but the conditions tested and simulated were still far from the in vivo environment. With this new study, we go deeper into the investigation process. In [14], authors limit the excitation frequency to a few $\mathrm{kHz}$ to avoid undesired charge displacements in the surrounding tissue. But this restriction was strictly assumption based on literary review of similar practices and further investigations must be under-taken to establish the optimal cutoff frequencies. 
In the first section of this manuscript, a ferromagnetic model is proposed for the simulation of magnetic behavior. This model gives the magnetization time variations and the frequency dependence of the composite hysteresis area (heat generated through the LFIH influence). Comparisons between simulations and measurements are proposed where, the ferromagnetic model parameters are set such as the most efficient excitation frequency. In the third section of the manuscript, multi-physics simulation results combined with experimental tests are reviewed to predict the LFIH influence on living tissues. Eventually, the ferromagnetic catheter is simulated to anticipate its behavior in the air and in the human body.

\section{MAGNETIC BEHAVIOR, CONTACTLESS HEAT CONVERSION}

\section{A. Magnetic model}

By mixing $\mathrm{Fe}_{3} \mathrm{O}_{4}$ particles to thermoplastic-base polymers, ferrimagnetic $3 \mathrm{D}$-printable composites can be obtained. $\mathrm{Fe}_{3} \mathrm{O}_{4}$ ferrimagnetic particles have remarkable properties, including their strong magnetic moment, biocompatibility and chemical stability. $\mathrm{Fe}_{3} \mathrm{O}_{4}$ particles are ferrimagnetic but below a permissible dimension threshold (a few nanometers) a superparamagnetic phase is observed. This form of magnetism is characterized by a complete disappearance of the coercivity and a magnetic behavior which can be simulated with a sigmoid Langevin-type equation [20]. In this study, where the objective is to convert low frequency electromagnetic energy into heat, it is better to avoid superparamagnetism by working with bigger size particles. However, a compromise has to be achieved since the composite texture also depends on the particle size and oversized particles may result in unprintable composites and extreme printing nozzle wear. A few micrometers is the adequate dimension to achieve this balance. According to their size, the $\mathrm{Fe}_{3} \mathrm{O}_{4}$ particles can be monocrystalline or polycrystalline, i.e. made out either of a single grain or of multiple grains. Each grain is divided into different magnetic domains. Under the influence of an external magnetic excitation. The stability of the magnetic domain's distribution is modified and domain wall motions, fusions, and nucleation take place all over the particle. The magnetic losses due to the magnetization cycles in $\mathrm{Fe}_{3} \mathrm{O}_{4}$ particles are highly frequency $f$ dependent. This dependence manifests itself while plotting the evolution of the material's magnetic state $\mathrm{M}$ as a function of the external tangent of the magnetic excitation field $H$, which in turn generates the hysteresis cycle $M(H)$. The hysteresis cycle area is equal to the magnetic losses, i.e. the energy consumed during a magnetization cycle. This energy is converted into heat. In polycrystalline specimens, diffusion mechanisms occurring during the crystal growth step gather inclusions and defects in the grain boundaries creating larger pinning sites hindering the domain wall motions and leading to a hardening of the magnetic properties. In single crystal specimens, defects and inclusions are smaller but a hysteresis cycle is still observed confirming that pinning processes are still happening [21].

Magnetic losses in $\mathrm{Fe}_{3} \mathrm{O}_{4}$ particles are due to magnetic flux variations. These flux variations have two origins:

- The external magnetic excitation field $H$ (macroscopic eddy currents).
- The domain wall motions in the magnetization processes (microscopic eddy currents).

In [14], unsuccessful LFIH tests on specimens made of polymer mixed with conductive but non-ferromagnetic particles confirmed the preponderant weight of the microscopic eddy currents contribution.

The working temperature of the endovenous varicose treatment is $120{ }^{\circ} \mathrm{C}$. Under such temperature, the electrical resistivity of the $\mathrm{Fe}_{3} \mathrm{O}_{4}$ particles is $0.50 \Omega . \mathrm{m}$ and the average magnetic permeability is close to 50 . A simple calculation based on skin depth at $10 \mathrm{kHz}$ and a relative permeability of 50 gives $1 \mathrm{~m}$. This large skin depth means a very low macroscopic eddy current density and confirms the absence of macroscopic eddy currents in the heat conversion. The simulation of the magnetic losses can be done by using methods developed for bulk ferrite ceramics. Due to their intrinsic constitution, ferrite ceramics exhibit high magnetic permeabilities and low electrical conductivities. Just like our ferromagnetic composite, bulk ferrite magnetic losses and heat generation are characterized by the predominance of the domain wall motion contribution. Eq. 1 below, has already demonstrated its ability to simulate correctly the dynamic magnetic behavior of bulk ferrites [22][25]. This equation has also been used with success for ferromagnetic composites [26][27]:

$$
\rho \frac{d B(t)}{d t}=H_{\text {surf }}(t)-f_{\text {quasi-static }}^{-1}(B(t))
$$

Where $H_{\text {surf }}$ is the surface tangent excitation field, $f_{\text {quasi- }}^{1}$ $\operatorname{static}(B(t))$ is a magnetic field contribution calculated using a quasi-static frequency independent hysteresis model and $\rho$ is a parametric constant depending on the nature and the geometry of the ferromagnetic specimen. The simulated hysteresis area is equivalent to the electrical energy converted into Joule losses during one magnetization cycle. Fig. 3 - b below depicts the hysteresis area vs. frequency curve (after normalization), Fig. 3 - c depicts the instantaneous heat power vs frequency curve (after normalization).

\section{B. Experimental tests, model adjustment}

To simulate the ferromagnetic behavior of new specimens using Eq. 1, $\rho$ the dynamic constant and the $f^{1}$ quasi-static parameters have to be set. The quasi-static behavior is observable as $f$ is getting close to 0 . For this contribution, we used the simulation method and the related parameters set in [14]. $\rho$ is obtained by comparisons to experimental results.

An overall 3D view of the experimental setup is depicted in Fig. 1 below:

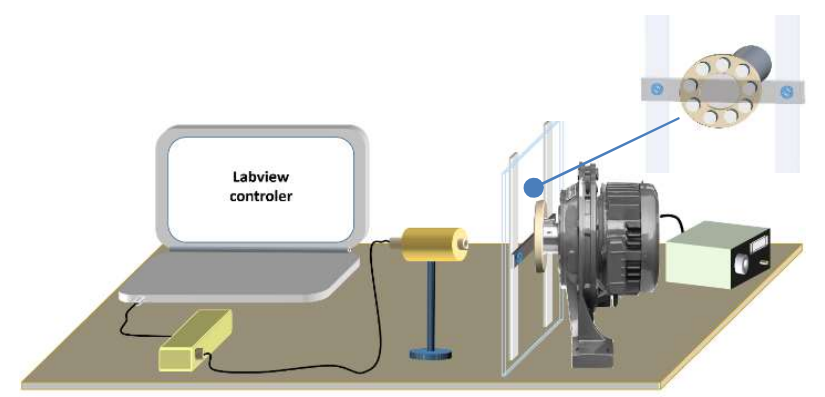

Fig. 1 - Experimental set-up.

$2 \times 15 \times 100 \mathrm{~mm}, 17 \mathrm{vol} \%$, ferromagnetic composite bands 
are subjected to an alternating magnetic field induced by a magnetic inductor made out of permanent magnets tightly fit to a high speed DC motor rotor. A high resolution thermal camera positioned on the opposite side of the DC motor, monitored the temperature variations [14]. A magnetic heating power is generated in the red zones of Fig. 2 left hand side.
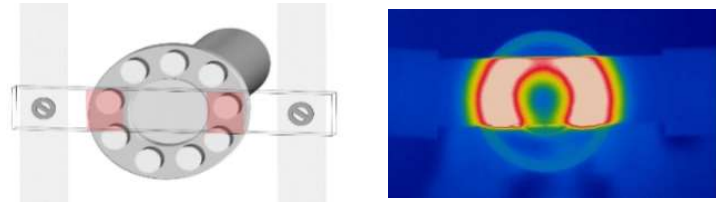

Fig. 2 - Simulated ferromagnetic composite band (left), thermal camera illustration (right).

A Comsol ${ }^{\circledR}$ simulation including all the thermal exchanges (conduction, radiation, air convection) was ran to estimate the tested specimen temperature variation [14]. The simulated parameters are given in Tab. 1:

Tab. 1 - Thermal simulation parameters.

\begin{tabular}{c|c|c|c|c|c|} 
Surface emission $\varepsilon$ & $\begin{array}{c}\text { Specific heat Cp } \\
\left(J \cdot \mathrm{kg}^{-1} \cdot K^{-1}\right)\end{array}$ & $\begin{array}{c}\text { Heat power density } \mathrm{P} \\
\left(\mathrm{W} \cdot \mathrm{m}^{-3}\right)\end{array}$ & $\begin{array}{c}\text { Thermal conductivity } \mathrm{\lambda} \\
\left(\mathrm{W} \cdot \mathrm{m}^{-1} \cdot \mathrm{K}^{-1}\right)\end{array}$ & $\begin{array}{c}\text { Transfer coefficient } \mathrm{h} \\
\left(\mathrm{W} \cdot \mathrm{m}^{-2} \cdot \mathrm{K}^{-1}\right)\end{array}$ & $\begin{array}{c}\text { Frequency } \\
(\mathrm{KHz})\end{array}$ \\
\hline 0.9 & 750 & $1.510^{6}$ & 0.4 & 25 & 2.3 \\
\hline 0.9 & 750 & $1.810^{6}$ & 0.4 & 25 & 4.2 \\
\hline
\end{tabular}

Comparisons simulations/measurements for the tAime variation of the heated zone temperature was used to set the Average Magnetic Heating Power (AMHP). Two frequencies were tested. The AMHP is equivalent to the magnetic losses plotted in Fig. 1. It is used to set $\rho$ as depicted in Fig. 4 below:

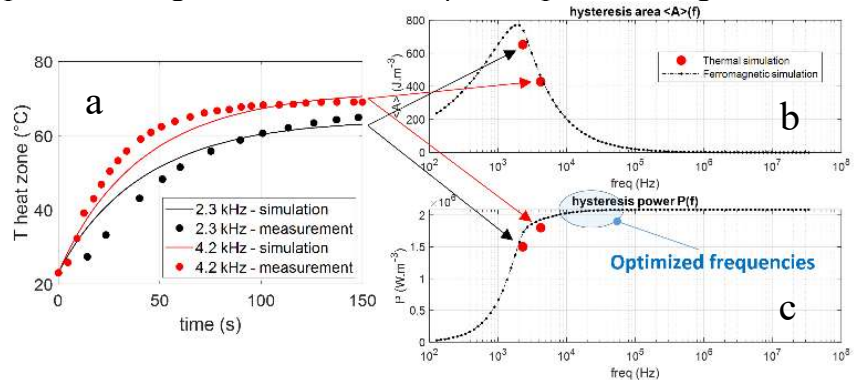

Fig. 3 - a Comparison simulation/measurement for the time dependence of the heat zone temperature, 3 - b Hysteresis area, 3 - c Magnetic power.

The best simulation results are obtained for a value of $\rho$ equal to 6 (Fig. 3). Once the magnetic simulation parameters are set, the LFIH optimized frequencies can be tested. This was done by opting for the lower frequency providing the maximum hysteresis losses. For the 17 vol\% composition tested here, the best frequency was $20 \mathrm{kHz}$ and the expected power close to 2.1 $10^{6} \mathrm{~W} \cdot \mathrm{m}^{-3}$

\section{HUMAN TISSUES BEHAVIOR UNDER THE LFIH TREATMENT}

Even if the magnetic composite permeability is high, the leakage magnetic excitation in the living surrounding tissues is generating charge displacements and local temperature increases. From a medical point of view, it is mandatory to anticipate the living tissue behavior under the influence of this dynamic magnetic field. The current density and the temperature variations have to be estimated precisely to be able to effectively apply treatment in the affected area. In this section, a Comsol ${ }^{\circledR}$ model is proposed to anticipate the human tissue behavior under the influence of the LFIH process. Experimental tests on conductive water and fresh animal muscle tissues are conducted as validation.

\section{A. FEM simulation of the human leg under the LFIH treatment}

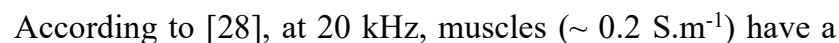

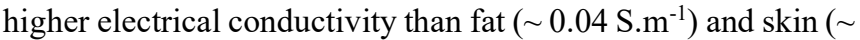

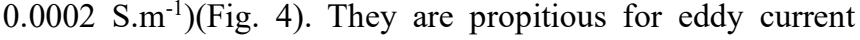
development and heat generation. To simplify the simulation and check the viability of the method in the worst case scenario, the human leg is simulated considering muscle as the only constituent. A small pancake coil ( $0.01 \mathrm{~m}$ radius, 2 turns) placed next to the leg (Fig. 6) was used for the generation of the magnetic excitation. The simulation results depicted in Fig. 5 have been obtained using the optimized magnetic field excitation. The physical properties of the simulation materials are given in Tab. 2 below.

Tab. 2 - Physical properties of the simulated materials.

\begin{tabular}{|c|c|c|c|c|c|c|c|}
\hline Object & Material & $\begin{array}{c}\text { Electrical } \\
\text { conductivity } \\
\left(\mathbf{S} \cdot \mathbf{m}^{-1}\right)\end{array}$ & $\begin{array}{c}\text { Rel. } \\
\text { Permittivity }\end{array}$ & $\begin{array}{c}\text { Rel. } \\
\text { Permeability }\end{array}$ & $\begin{array}{c}\text { Heat capacity } \\
\text { at cst pressure } \\
\left(\mathbf{J} \cdot \mathbf{K g}^{-1} \cdot \mathbf{K}^{-1}\right)\end{array}$ & $\begin{array}{c}\text { Density } \\
\left(\mathbf{K g} \cdot \mathbf{m}^{-\mathbf{3}}\right)\end{array}$ & $\begin{array}{c}\text { Thermal } \\
\text { conductivity } \\
\left(\mathbf{W} \cdot \mathbf{m}^{-1} \cdot \mathbf{K}^{-\mathbf{1}}\right)\end{array}$ \\
\hline Coil & Copper & 6107 & 1 & 1 & 385 & 8.9103 & 401 \\
\hline Leg & Muscle & 0.3 & 23000 & 1 & 3421 & 1090 & 0.49 \\
\hline
\end{tabular}

The first simulation results showed a large heat generation in the excitation coil due to the Joule losses generated by the intense electrical current flowing through. After a few seconds, the copper temperature is already extreme and heat is diffusing to the leg through contactless exchanges. This heat transfer is undesirable since in the LFIH prototype the excitation field is created by permanent magnets, and it is inactive thermically. To improve the simulation accuracy, the contribution of the eddy currents considering only, the isolated coil was tested in the next simulation. Once the heat generated by the coil was removed, the initial temperature was set to $37^{\circ} \mathrm{C}$ and the magnetic flux density magnitude to $0.2 \mathrm{~T}\left(1.610^{5} \mathrm{~A} \cdot \mathrm{m}^{-1}\right)$. According to the simulation almost no temperature variation was observed even after multiple seconds $\left(<0.05{ }^{\circ} \mathrm{C}\right)$.

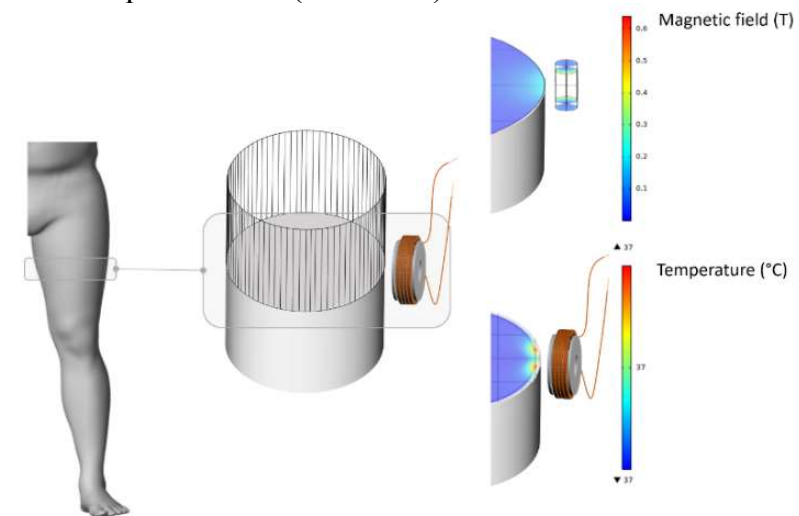

Fig. 4 - Geometry of the model and distribution of the temperature after 10s.

\section{B. Experimental validation}

Experimental tests were proposed to validate the simulation results described in the previous section. The experimental setup is shown in Fig. 1 and described in detail in [14][15]. A 16 magnets inductor was tightly mounted on the high speed DC motor rotor. A high amplitude sinusoidal magnetic excitation (160 kA.m ${ }^{-1}$ measured close to the permanent magnets) was obtained for a frequency up to $4.2 \mathrm{kHz}$. A high resolution thermal camera (Optris Xi400, Berlin, Germany) was 
positioned in front of the high speed DC motor to observe the temperature variations. Experimental tests were perfomed using conductive water and animal muscle tissues as seen in Fig. 5.

According to [29] the electrical conductivity $\sigma$ of human muscles under the influence of a $20 \mathrm{kHz}$ alternating magnetic field is around $0.3 \mathrm{~S} . \mathrm{m}^{-1}$. A solution of $0.3 \mathrm{~S}^{-1} \mathrm{~m}^{-1}$ conductive water was prepared and tested. No temperature variation was observed, even after a long period of $4.2 \mathrm{kHz}$ high amplitude magnetic excitation. To increase the inductive heating effect, the $\sigma=0.3 \mathrm{~S} . \mathrm{m}^{-1}$ water was replaced with a $\mathrm{NaCl}$ saturated solution of $\sigma=3.6 \mathrm{~S} . \mathrm{m}^{-1}$, but again an insignificant thermal effect was observed after $30 \mathrm{~s}$.

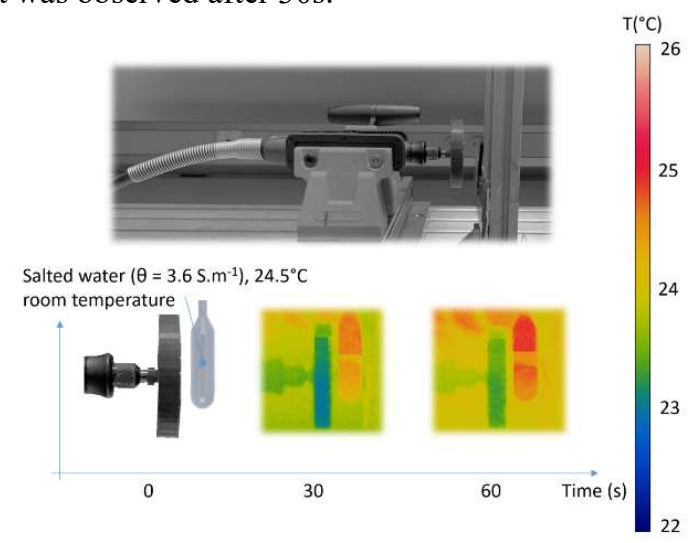

Fig. 5 - Temperature variations in the conductive water.

The same tests were performed to validate the simulation results on a sample of animal muscle tissue. A thermocouple and the thermal camera were used simultaneously to monitor the temperature variations as depicted in Fig. 6.

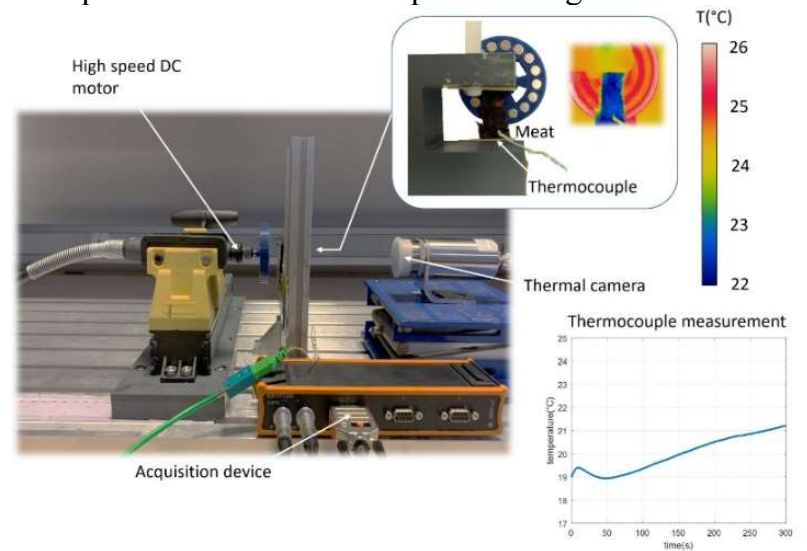

Fig. 6 - Temperature variations in the meat.

The experimental results were consistent with the simulation ones. The temperature variations recorded by the thermal camera during the LFIH treatment were very small. The thermocouple shows a slight temperature elevation as illustrated on the right bottom hand plot of Fig. 6 but after several tests, we observed an inconsistency in the slopes $(\mathrm{d} \theta / \mathrm{dt})$ probably due to undesired inductive behaviors.

\section{THERMAL BEHAVIOR OF THE CATHETER UNDER THE INFLUENCE OF THE LFIH TREATMENT}

In our set-up, the excitation is limited to $4.2 \mathrm{kHz}$. According to the model described in the first section of this manuscript, the LFIH optimal frequency is close to $20 \mathrm{kHz}$ (significantly higher). In this section, simulations are proposed to anticipate the catheter magneto/thermal coupling in the air and in the human body under a $20 \mathrm{kHz}$ magnetic excitation.

\section{A. Simulation of the Ferromagnetic catheter in the air}

A first simulation test was done at $4.2 \mathrm{kHz}$. The initial temperature was set to $23{ }^{\circ} \mathrm{C}$. A $1.5 \mathrm{~mm}$ radius catheter was divided into five parts (Fig. 7) of 10, 12, 6.5, 12 and $10 \mathrm{~mm}$ respective lengths.

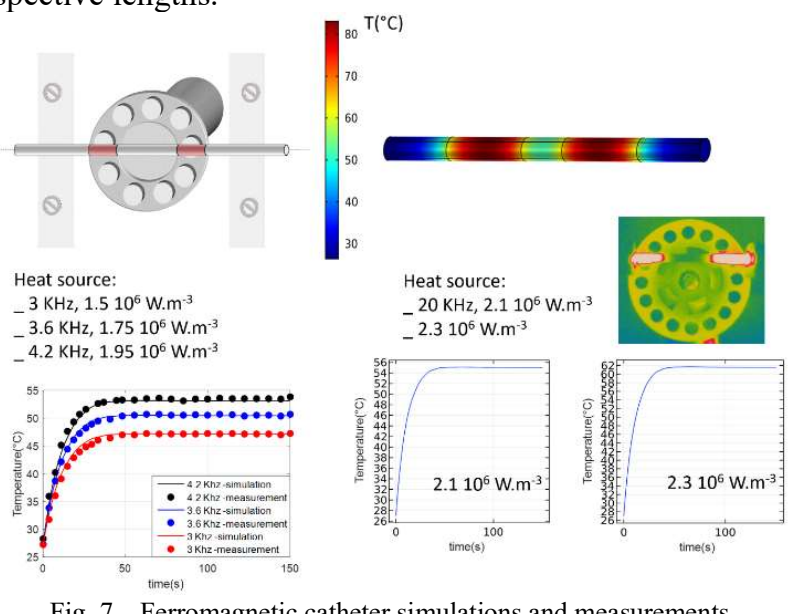

In parallel to this simulation, a catheter shape $(\mathrm{ABS}+17$ vol\% particles) ferromagnetic composite specimen was tested $[14][15]$ at the same frequency. The physical properties of the ferromagnetic catheter are given in Tab. 2. To adjust the experimental results observed at $3,3.6$ and $4.2 \mathrm{kHz}$, a magnetic heating power of $1.5,1.75$, and $1.9510^{6} \mathrm{~W} . \mathrm{m}^{-3}$ was imposed in the red zones (Fig. 7). These heating power values were slightly higher $(\sim 10 \%)$ than those observed in simulation (probably due to errors in the parameters estimation)(see Fig. 4).

Then, the excitation frequency was set to $20 \mathrm{kHz}$ and the heating source to $2.110^{6} \mathrm{~W} . \mathrm{m}^{-3}$. In simulation (Fig. 7), a maximum of $55^{\circ} \mathrm{C}$ was reached after a LFIH test of approximately $50 \mathrm{~s}$. A last test was done at $2.310^{6} \mathrm{~W} \cdot \mathrm{m}^{-3}$ to consider the $10 \%$ adjustment and $62^{\circ} \mathrm{C}$ was reached. This temperature is still far from the $120{ }^{\circ} \mathrm{C}$ required but in the air, the thermal exchanges are very different.

\section{B. Simulation of the ferromagnetic catheter in the blood vessel}

The thermal behavior of the ferromagnetic catheter was simulated in a human body environment. A blood flow path was considered along the catheter with an initial blood temperature set to $37^{\circ} \mathrm{C}$. The dynamic viscosity was set to $3.510^{-3} \mathrm{~Pa}$.s, and the pressure to $1.05 \mathrm{~atm}$. The time variation of the maximum temperature on the surface of the catheter is depicted in Fig. 8. For a $0.1 \mathrm{~m} . \mathrm{s}^{-1}$ blood flow, a steady state is obtained close to $80^{\circ} \mathrm{C}$. We were not expecting such a high difference between the "in the air" and the "in the blood vessel" temperatures. Intuitively, the blood vessel thermal exchanges is assumed to be largely superior compared to the "in the air" ones reducing the blood vessel temperature. Actually, the small difference between the catheter and the blood vessel cross-sections, the relatively weak blood flow and the $37^{\circ} \mathrm{C}$ temperature of the boundaries are limiting the thermal transfers and favor the increase of the temperature. To accurately incorporate the blood flow, fluid mechanics must be implemented as blood will be moving in the physical environment having a large impact on 
thermal transfer.

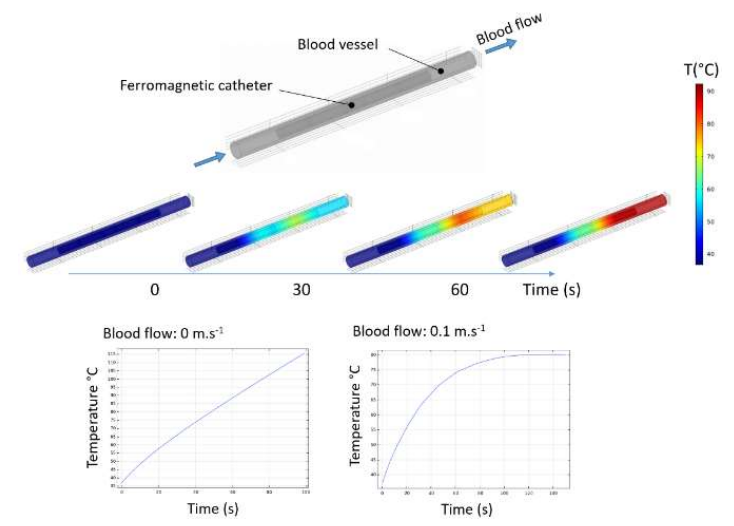

Figure 9: Temperature versus time for needle composites in the blood vessel.

\section{CONCLUSIONS}

Endovenous ablation uses thermal energy to heal varicose veins. Ablation is safe, less invasive than surgery, and leaves virtually no scars. The interest in these new methods is significant, and research progress is highly aniticipated. In this study, additive manufacturing principles have been used to build a ferromagnetic catheter (mix of ABS base to $\mathrm{Fe}_{3} \mathrm{O}_{4}$ ferromagnetic particles). Under the influence of a dynamic magnetic field, the ferromagnetic catheter works as a contactless heat source which can be used to cauterize the damaged blood vessels. The temperature targeted is $120^{\circ} \mathrm{C}$ with time constants lower than a few seconds. In the first part of this manuscript, a magnetic simulation method has been proposed to optimize the frequency of the magnetic waveform. $20 \mathrm{kHz}$ has been set for a $17 \%$ vol. particle specimen. The converted power is expected to be $2.1 \times 10^{6} \mathrm{~W} \cdot \mathrm{m}^{-3}$. Such power corresponds to an approximately $20 \%$ improvement. Then, the LFIH influence on the human body was studied. Simulations were provided and showed unsignificant temperature variations. These simulation results were confirmed experimentally on conductive water and animal tissues.

In the last section, a FEM simulation of the magnetic catheter in the air and in the human body gave $55^{\circ} \mathrm{C}$ and $80{ }^{\circ} \mathrm{C}$ respectively. It is evident that the $120^{\circ} \mathrm{C}$ is still not reached but performances improvement can be expected from composites of higher particle content. Up to $35 \%$ vol. particles seems possible but it will come with technological difficulties.

\section{REFERENCES}

[1] Standard A. F2792, "Standard Terminology for Additive Manufacturing Technologies. West Conshohocken", Pa, USA: ASTM International, 2012.

[2] G.N. Levy, R. Schindel, J.P. Kruth, "Rapid manufacturing and rapid tooling with layer manufacturing (LM) technologies, state of the art and future perspectives", CIRP Annals-Manuf. Technol., vol. 52 iss.2, pp. 589-609, 2003.

[3] SK. Malhotra, K. Goda, MS. Sreekala, "Part One Introduction to Polymer Composites", Polymer Composites. 1st ed.1. Wiley-VCH, 2012.

[4] Y. Arbaoui, P. Agaciak, A. Chevalier, V. Laur, A. Maalouf, J. Ville, P. Roquefort, T. Aubry, P. Queffelec, "3D printed ferromagnetic composites for microwave applications", J. of Mat. Sci., vol. 52, pp. 4988-4996, 2017.

[5] B. Khatri, K. Lappe, D. Noetzel, K. Pursche, T. Hanemann, "A 3Dprintable polymer-metal soft-magnetic functional composite development and characterization”, Mat., vol. 11, iss. 2, 189, 2018.

[6] CC. Corten, MW. Urban, "Repairing Polymers Using Oscillating Magnetic Field”, Adv. Mater., vol. 21, pp. 5011-5015, 2009.
[7] T. Duenas, J. Schlitter, N. Lacevic, A. Jha, K. Chai, "Ballistic Missile Defense System Solutions Using Remendable Polymers", Time Dep. Constitutive Behavior and Fracture/Failure Processes, Conf. Proc. of the Soc. Exp. Mech. Ser., Springer New York, 15, 267-273 (2011).

[8] T. Duenas, A. Enkea, K. Chaia, M. Castelluccib, VB. Sundaresanb, F. Wudlc, EB. Murphyc, A. Mald, JR. Alexandare, A. Corderf, TK. Ooifg, "Smart Self-Healing Material Systems Using Inductive and Resistive Heating in Smart Coatings III", ACS Symp. Am. Chem. Soc., Wash. DC, 1050, pp. 45-60, 2010.

[9] L. Moser, P. Mitschang, AK. Schlarb, "Induction welding of thermoplastic polymer composites using robotic techniques", SAMPE J., vol. 44 iss. 5, pp. 43-49, 2008

[10] S. Yarlagadda, BK. Fink, JW. Gillespie, "Resistive susceptor design for uniform heating during induction bonding of composites", J. Therm. Compos. Mater., vol. 11, pp. 321-337, 1998

[11] L. Moser, P. Mitschang, "In the shifting magnetic field", Kunstst. Int., vol. 100 iss. 7, pp. 26-28, 2010

[12] M. Wacker, L. Moser, AK. Schlarb, HR. Tradt, "Flexible 3D joining process for complex fibre composite components", Join. Plast., vol. 2 iss. 4, pp. 266-271, 2008.

[13] LM. Bollig, PJ. Hilpisch, GS. Mowry, BB. Nelson-Cheeseman, "3D printed magnetic polymer composite transformers”, J. of Mag. and Mag. Mat., vol. 442, pp. 97-101, 2017.

[14] Z. Xiang, K.I. Jakkpat, B. Ducharne, J.F. Capsal, N.D. Schiava, J.F. Mogniote, P.J. Cottinet, P. Lermusiaux, M.Q. Le, "Enhancing lowfrequency induction heating effect of magnetic composites for medical applications", polymers 2020, 12(2), 386, 2020.

[15] Z. Xiang, B. Ducharne, N.D. Schiava, J.F. Capsal, P.J. Cottinet, G. Coativy, P. Lermusiaux, M.Q. Le, "Induction Heating-based LowFrequency Alternating Magnetic Field: High Potential of Ferromagnetic Composites for Medical Applications", Mat. \& Des., Vol. 174, 107804, 2019.

[16] R.H. Jones, P.J.Carek, "Management of varicose veins", Am. Fam. Phys., vol. 78, n¹1, pp. 1289-1294, 2008

[17] R. Van Den Bos, M.G. de Maeseneer, "Endovenous thermal ablation for varicose veins: strengths and weaknesses", Servier Phlebolymphology, vol. 19 , iss. 4 , pp. 163-169, 2012

[18] J.-J. Liu, L.-H. Fan, D.-C. Xu, X. Li, Z.-H. Dong, W.-G. Fu, "The endovenous laser treatment for patients with varicose veins", Pak. J. Med. Sci., voL. 32, iss. 1, pp. 55-58, 2016.

[19] M.P. Goldman, "Closure of the greater saphenous vein with endoluminal radiofrequency thermal heating of the vein wall in combination with ambulatory phlebectomy: preliminary 6-month follow-up", Dermatol. Surg., vol. 26, iss. 5, pp. 452-456, 2001.

[20] L. Néel, "Propriétées magnétiques des ferrites; Férrimagnétisme et antiferromagnétisme”, An. de Physique (Paris), vol. 3, pp. 137-198, 1948.

[21] J. Wan, X. Chen, Z. Wang, X. Yang, Y. Qian, “A soft-template-assisted hydrothermal approach to single-crystal $\mathrm{Fe}_{3} \mathrm{O}_{4}$ nanorods", J. Cry. Gro., vol. 276 , iss. 3-4, pp. 571-576, 2005.

[22] B. Ducharne, G. Sebald, D. Guyomar, G. Litak, "Fractional model of magnetic field penetration into a toroidal soft ferromagnetic sample", Int. J. of Dyn. And Cont., pp. 1-8, 2017.

[23] M. A. Raulet, B. Ducharne, J.P. Masson, and G. Bayada, "The magnetic field diffusion equation including dynamic hysteresis: a linear formulation of the problem", IEEE Transactions on Magnetics, vol. 40, $\mathrm{n}^{\circ}$ 2 , pp. $872-875,2004$

[24] B. Ducharne, G. Sebald, D. Guyomar, G. Litak "Dynamics of magnetic field penetration into soft ferromagnets", Journal of Applied Physics, pp. 243907, 2015.

[25] P. Tenant, J.J. Rousseau, "Dynamic model of magnetic materials applied on soft ferrites", IEEE Trans. on. Pow. Elec., vol. 13, iss. 2, 1998.

[26] Z. Xiang, B. Gupta, M.Q. Le, P.J. Cottinet, B. Ducharne, "Hysteresis model of 3D printed magnetic particles based polymer composite materials", IEEE Trans. on. Mag, 2018 IEEE int. Mag. Conf. (INTERMAG), Singapore.

[27] B. Gupta, B. Ducharne, G. Sebald, T. Uchimoto, "Magnetic lump model for the hysteresis frequency dependence of a polymer matrix", proceeding of the $21^{\text {st }}$ international conference on the computation of electromagnetic fields COMPUMAG, Daejeon (S. Korea), 2017.

[28] M. R. Mahfouz, M. J. Kuhn, G. To, and A. E. Fathy, "Integration of UWB and wireless pressure mapping in surgical navigation," IEEE Trans. Microw. Theory Tech., vol. 57, no. 10, pp. 2550-2564, 2009.

[29] M. R. Mahfouz, M. J. Kuhn, G. To, and A. E. Fathy, "Integration of UWB and wireless pressure mapping in surgical navigation," IEEE Trans. Microw. Theory Tech., vol. 57, no. 10, pp. 2550-2564, 2009 